ORIGINAL ARTICLE

\title{
Fall Prevalence and Associated Risk Factors in Geriatric Population
}

\author{
HAFSAH GUL KHATTAK ${ }^{1}$, HAFSAH ARSHAD ${ }^{2}$, KINZA ANWAR ${ }^{3}$, YASER MAJEED ${ }^{4}$ \\ ${ }_{1,2}$ Lecturer, University of Lahore Department of Physical Therapy, Islamabad \\ ${ }^{3}$ Senior lecturer, Riphah International University, Islamabad \\ ${ }^{4}$ Physiotherapist, Special education school Hamza Camp, Rawalpindi \\ Correspondence to Dr. Hafsah Gul Khattak, Email: hafsah.gul@uipt.uol.edu.pk, Tel. 0315-9828868
}

\begin{abstract}
Aim: To determine the prevalence of fall among geriatric population and to find out risk factors associated with fall. Method: A cross-sectional study was conducted with a sample of 223, raised through non-probability convenient sampling technique. The inclusion criteria were older adults both genders, aged 60 years and above. The exclusion criteria were older persons with severe and uncontrolled co morbidities that include diabetes, hypertension, memory impairment, stroke, psychiatric disorders, and use of any walking aid. Data was collected through semi structured questionnaire. Fall risk assessment scale was used to categorize fall risk status in older persons. Data was analyzed using SPSS 24. Descriptive statistics and Chi-square test were applied.

Results: The overall mean age of participants was $67.61 \pm 5.64$ years. Out of 223 participants, females were $134(60.1 \%)$ and $89(39.9 \%)$ were males. The prevalence of falls reported in elderly was $42.6 \%$. Most prevalent fall were reported under category of 1-2 falls, out of which females had $43(32.1 \%)$ and males had $29(32.6 \%)$ falls. Among study participants $87(39.0 \%)$ were in high-risk group while $136(61.0 \%)$ participants were in low-risk group. Furthermore, weak eyesight, use of medications, vertigo/imbalance, and chronic medical conditions $(p<0.05)$ were considered as most significant risk factors with fall.

Conclusion: The study showed significant number of older adults who had fall. Female were at high risk of fall. Weak eyesight, use of medications, vertigo/imbalance, and chronic medical conditions were found to be most prevalent risk factors associated with fall.

Keywords: Fall, geriatrics, aging, fall risk, prevalence, old age
\end{abstract}

\section{INTRODUCTION}

The population aging is chief demographic phenomenon worldwide in the late $20^{\text {th }}$ and early $21^{\text {st }}$ century. World health organization (WHO), described older adult population as those aged 60 or over years presents with growth rates of about 2.4 percent in comparison to the general population of $1.7 \%{ }^{1}$. Globally upsurge of geriatric populations observed, In Pakistan, 12.13 million people are above 65 years of age, and expected to increase up to 18 million by $2050^{2}$. Although aging is irreversible normal physiological phenomenon, several health and mental conditions are incapacitating for the elderly population. Among them falls are considered as most common geriatric syndrome and associated with increased mortality and morbidity 3,4 .

Fall is described as sudden change in position of a person to a lower level, with failure to avoid this unintended change from the initial position ${ }^{5}$. Worldwide, fall prevalence among elderly population is 18 to $33 \%$ and it is reported that 6 to $15 \%$ persons will have frequent falls ${ }^{6}$. Furthermore, statistics of reported 28 to 35 percent fall among aged above 65 years and 32 to 42 percent fall among above 70 years per annum. Annually 19.3\%, 22.4\% and $20 \%$ of low fall incidence is reported in developing countries like China, United Kingdom and Japan, respectively ${ }^{7}$. The incidence rate of fall injuries in Pakistan is 8.85 per thousand annually reported by National Injury Survey Pakistan ${ }^{8}$. In developing countries, increase in number of elderly population considers as major concern as it difficult to maintain health due to limited medical

Received on 27-03-2021

Accepted on 04-08-2021 resources ${ }^{7}$. In older adults $40 \%$ of traumatic injuries-related hospital admissions are linked to falls which can result in pain, lacerations, bruising, fractures, soft issue injuries, in severe cases can lead to intracranial bleeding, dependent ADLs, long term disability and decease ${ }^{9,10}$.

Previous studies stated several intrinsic and extrinsic risk factors likely to cause fall in elderly. Identified risk factors include increased age, previous fall history, deficits in environment hazards (uneven surface, low light, greasy floor), several health-related conditions comprising muscle weakness, vertigo, balance and gait impairment, hearing disorders, visual deficits, memory and sensory and proprioception loss, chronic medical conditions like diabetes mellitus \& hypertension, orthostatic hypotension, and osteoporosis ${ }^{4,10}$. Literature also highlighted the use of certain medications are also associated with increase in fall among elderly. Commonest drugs are psychotropic and antidepressant drugs which causes side effects i.e., sedation, balance impairment and coordination. Additional diuretics and beta-blockers under category of cardiovascular drugs results or lead to postural hypotension and fall. Antihistamines and anticholinergic drugs may alter the cognitive skills, blurred vision thus enhancing the risk of falls among older adults ${ }^{10,11,12}$. Moreover drugs used by cardiac patients has side effects of postural hypotension, blurred vision further increasing the fall risk in older people ${ }^{12}$ due to this background knowledge and limited literature on fall of prevalence among geriatric population in Pakistan.

The current study was planned to find out the prevalence of fall among elderly population. The study was also aimed to identify fall prevalence among gender and to explore the associative risk factor related to fall. 


\section{METHODOLOGY}

A cross-sectional study was conducted from September 2018 to February 2019. Ethical approval for the study was obtained from NCS University System, Peshawar. The sample size was calculated using epi tool with $95 \%$ confidence interval $(\mathrm{Cl})$ and $5 \%$ of margin error. Data was raised through non-probability convenient sampling technique. The inclusion criteria were older adults both male and female, aged 60 years and above, home resident, able to communicate and understand verbally not involved in any physical fitness and rehabilitation program and willing to participate. Those excluded who were bed bound, with severe and uncontrolled co morbidities that include diabetes, hypertension, severe memory impairment and dementia, stroke, psychiatric disorders, depression and use of any walking aid. All study participants were explained and describe about the study purpose and nature and data was collected after taking written informed consent.

Data was collected using semi structured questionnaire in English and Urdu Version that comprised of 3 parts. Close-ended questions were included, with 'Yes and No as options. Pre-pilot study was conducted to check validity of questionnaire among 10 elderly participants and then the questionnaire was developed in its final form. First part includes socio-demographic characteristics of participants. Second part was related to fall profile and fall risk assessment scale. Fall risk assessment scale was used to categorize and identify and fall risk status in older persons. The participants whose score less than 10 were included in low-risk group, whereas score greater than 10 was included in high-risk group. Third part includes risk factors for fall including weak eyesight, medications, hearing problem, vertigo/imbalance, fear of fall, chronic medical condition, memory impairment.

Statistical analysis: Data was analyzed using SPSS 24. Descriptive statistics, frequencies and percentages mean, and standard deviation were calculated for qualitative and quantitative variables like socio demographic characteristics, fall profile, risk factors for fall including weak eyesight, medications, hearing problem, vertigo/imbalance, fear of fall, chronic medical condition, and memory impairment. To find out the association of fallers and non- fallers with various risk factors chi square test was conducted. The $\mathrm{p}$ value less than 0.05 was considered significant.

\section{RESULTS}

Of the 246 participants approached, out of which 223 participants completed the questionnaire giving a response rate of $90.6 \%$ in our study. Of them, majority $134(60.1 \%)$ were females and 89 (39.9\%) were males. The overall mean age was $67.61 \pm 5.64$ years. Furthermore, 120 (53.8\%) participants were of in age group of 65-69 years. Majority of study participants had primary education $76(34.1 \%)$, retired $188(84.3 \%)$, and lived in a nuclear family structure $114(51.1 \%)$. Sociodemographic characteristics of study participants were displayed in Table 1.

The prevalence of falls reported in elderly past 12 months was total of $95(42.6 \%)$ falls. Among the fallers, Table 3: Risk factors for falling
$37(38.9 \%)$ were males and $58(61.1 \%)$ were females. Among them, 72(75.7\%) participants stated at least 1-2 falls and $128(57.4 \%)$ had no history of fall. Based on the total scores obtained from Fall Risk Assessment scale, in the high-risk group, there were 52 (38.8\%) were females and $35(39.3 \%)$ were males. In the low-risk group, there were $82(61.2 \%$ ) females and $54(60.7 \%$ ) were males (Table 2).

Most prevalent risk factors observed in our study were weak eyesight, use of medications, vertigo/imbalance, and chronic medical conditions. The detail of risk factors was shown in Table 3.

Table 4 shows evaluated $p$-value for association of risk factors with falling.

Table 1: Demographic Characteristics of Participants
\begin{tabular}{|l|l|l|}
\hline Variables & $\mathbf{n = 2 2 3}$ & $\%$ \\
\hline Age & & \\
$60-64$ & 75 & 33.6 \\
$65-69$ & 120 & 53.8 \\
$70-74$ & 21 & 9.4 \\
75 and above & 7 & 3.1 \\
\hline Gender & & \\
Male & 89 & 39.9 \\
Female & 134 & 60.1 \\
& & \\
\hline Marital status & 190 & \\
Married & 25 & 85.2 \\
Widowed & 8 & 11.2 \\
Divorced & & 3.6 \\
\hline Education & 68 & \\
Illiterate & 76 & 30.5 \\
Primary & 44 & 34.1 \\
Secondary & 35 & 19.7 \\
Graduate and above & & 15.7 \\
\hline Occupation & 35 & \\
Working & 188 & 15.7 \\
Retried/Non-working & & 84.3 \\
\hline Type of family & 114 & 51.1 \\
Nuclear family & 91 & 40.8 \\
Joint family & 18 & 8.1 \\
Extended Joint family & 18 & \\
\hline
\end{tabular}

Table 2: Fall Profile

\begin{tabular}{|l|l|l|}
\hline Falls & Female $\mathbf{n = 1 3 4}$ & Male $\mathbf{n = 8 9}$ \\
\hline Number of falls & & \\
No fall & $76(56.7 \%)$ & $52(58.4 \%)$ \\
$1-2$ & $43(32.1 \%)$ & $29(32.6 \%)$ \\
$3-4$ & $15(11.2 \%)$ & $08(9.0 \%)$ \\
\hline Groups & & \\
High risk & $52(38.8 \%)$ & $35(39.3 \%)$ \\
Low risk & $82(61.2 \%)$ & $54(60.7 \%)$ \\
\hline Location & $90(63.4 \%)$ \\
Inside Home & $52(36.6 \%)$ \\
Outside home & $65(45.8 \%)$ \\
\hline Time & $12(8.4 \%)$ \\
Morning & $20(14.1 \%)$ \\
Afternoon & $45(31.7 \%)$ \\
Evening & \multicolumn{2}{|}{} \\
Night & $98(69.0 \%)$ \\
\hline Hospital visits after a fall & \\
Yes & $44(31.0 \%)$ \\
No &
\end{tabular}




\begin{tabular}{|l|l|l|l|}
\hline \multicolumn{2}{|l|}{ Risk factor } & Female n (\%) & Malen (\%) \\
\hline Weak eyesight & Yes & $37(63.8)$ & $22(59.5)$ \\
& No & $21(36.2)$ & $15(40.5)$ \\
\hline Medications & Yes & $42(72.4)$ & $25(67.6)$ \\
& No & $16(27.6)$ & $12(32.4)$ \\
\hline Hearing Problem & Yes & $18(31.0)$ & $15(40.5)$ \\
& No & $40(69.0)$ & $22(59.5)$ \\
\hline Vertigo/Imbalance & Yes & $35(60.3)$ & $20(54.1)$ \\
& No & $23(39.7)$ & $17(45.9)$ \\
\hline Fear of fall & Yes & $25(43.1)$ & $12(32.4)$ \\
& No & $33(56.9)$ & $25(67.6)$ \\
\hline Chronic Medical Conditions & Yes & $45(77.6)$ & $28(75.7)$ \\
& No & $13(22.4)$ & $9(24.3)$ \\
\hline Memory Impairment & Yes & $23(39.7)$ & $08(21.6)$ \\
& No & $35(60.3)$ & $29(78.4)$ \\
\hline
\end{tabular}

Table 4: Association between Risk factors and fall

\begin{tabular}{|l|l|l|l|l|}
\hline Risk factor & & Fallers n (\%) & Non-Fallersn (\%) & p-value \\
\hline Gender & Male & $37(38.9)$ & $52(40.6)$ & $0.002^{* \star *}$ \\
& Female & $58(61.1)$ & $76(59.4)$ & \\
\hline Weak eyesight & Yes & $59(62.1)$ & $47(36.7)$ & $0.013^{* * *}$ \\
& No & $36(37.9)$ & $81(63.3)$ & \\
\hline Medications & Yes & $67(70.5)$ & $75(58.6)$ & $0.001^{* * *}$ \\
& No & $28(29.5)$ & $53(41.4)$ & \\
\hline Hearing Problem & Yes & $33(34.7)$ & $35(27.3)$ & 0.375 \\
& No & $62(65.3)$ & $93(72.6)$ & \\
\hline Vertigo/Imbalance & Yes & $55(57.9)$ & $85(66.4)$ & $0.008^{* * *}$ \\
& No & $40(42.1)$ & $43(33.6)$ & \\
\hline Fear of fall & Yes & $37(57.0)$ & $34(42.0)$ & 0.273 \\
& No & $58(43.0)$ & $47(58.0)$ & \\
\hline Chronic Medical Conditions & Yes & $73(76.8)$ & $78(61.0)$ & $0.005^{* * *}$ \\
& No & $22(23.2)$ & $50(39.0)$ & \\
\hline
\end{tabular}

\section{DISCUSSION}

The present study aimed to determine the prevalence of fall among older people in Pakistan and to find out the associated risk factors. The overall prevalence of fall in our study was $42.6 \%$. Sharif et. al found $50.8 \%{ }^{10}$, Hamed Mortazavi and his colleagues in their survey found $35.7 \%{ }^{13}$, Pothiraj Pitchai et al found over all prevalence $24.98 \%{ }^{3}$, Carlos $H$. Orces mentioned $34.7 \%$ fall prevalence $^{14}$, Melissa Pirrie et al stated $34.5 \%{ }^{15}$ and Hong Wu et found $19.8 \%$ fall prevalence of among elderly population ${ }^{16}$.

Our study results showed that the prevalence of fall was greater among elderly females and at high risk as compared to males, fall prevalence increased with progressing age. Our study findings are consistent with previous studies that found higher prevalence of fall was among females $4,10,14,17-19$. Pothiraj Pitchai et al reported that most of the falls occurred in the morning time ${ }^{3}$. This finding supports our current study results of 65(45.8\%) falls occurring in morning. Furthermore, several other research studies were inconsistent with our results 17,20,21,22.

Additionally, our study showed most prevalent risk factors related to fall were weak eyesight, use of medications, vertigo/imbalance, and chronic medical conditions. Nirmala Gamage et al in their survey found associated risk factors of fall were age, gender, diabetes mellitus, Gait and Balance impairment or foot abnormalities, antihypertensive drugs and at least one long-term use of medications ${ }^{17}$. Pradnya Dhargave et al highlighted most prevalent risk factors in their study related to fall were previous fall history, poor vision, multiple medications use, walking aids, chronic diseases vertigo and balance deficient among elderly adults ${ }^{4}$. Caroline Lukaszyk et al reported in their work use of medications three or more, arthritis, macular degeneration, depression and previous history of stroke were fall related factors among elderly (19). Suleiman I Sharif et al in their survey found use of 1-4 medications and increased number was significant risk factor among fallers ${ }^{10}$. Zhang $D$ et al stated difficulty in walking or standing, visual deficit, mild cognitive impairment, urinary incontinence and stroke were prominent risk factors ${ }^{23}$. Shirley Musich et al mentioned recurrent fall, use of 2 or more class of medications, low health status and advanced aged were prominent causative factors linked to fall ${ }^{12}$. Caroline Lukaszyk and coworkers in their review found lack of activity, history of CVA, hearing impairment, head injury and urinary incontinence were significant factors associated with fall ${ }^{24}$.

The current study was a cross sectional study so cause and relationship between fall and its risk factors could not be described. Assessment of physical activity levels and psychological levels of older adults were not done. Future studies should investigate injury and disability because of fall in older adults.

\section{CONCLUSION}

The study showed significant number of older adults who had fall. Female were at high risk of fall. Weak eyesight, use of medications, vertigo/imbalance, and chronic medical conditions were found to be most prevalent risk factors associated with fall. Among elderly population under consideration fall was prevalent further efforts should be 
made to reduce incidence, identify at risk and causative factors, and measures should be taken to increase awareness and provide guidance about fall and their health consequences among elderly population.

Conflict of interest: Nil

\section{REFERENCES}

1. Ocampo-Chaparro JM, Zapata-Ossa HdJ, Cubides-Munévar ÁM, Curcio CL, Villegas JdD, Reyes-Ortiz CA. Prevalence of poor self-rated health and associated risk factors among older adults in Cali, Colombia. Colombia Médica. 2013;44(4):224-31.

2. PAKISTAN ECONOMIC SURVEY 2014-15,Population, Labor Force and Empowerment: Ministry of Finance, Government of Pakistan;2014-2015 [Available from: http://www.finance.gov.pk/survey_1415.html. .

3. Pitchai P, Dedhia HB, Bhandari N, Krishnan D, D'Souza NRJ, Bellara JM. Prevalence, risk factors, circumstances for falls and level of functional independence among geriatric population-A descriptive study. Indian journal of public health. 2019;63(1):21.

4. Dhargave P, Sendhilkumar R. Prevalence of risk factors for falls among elderly people living in long-term care homes. Journal of clinical gerontology and geriatrics. 2016;7(3):99103.

5. Agarwalla $R$, Saikia AM, Pathak R, Islam F, Borah $M$, Parashar M. A cross sectional study on assessment of falls in community dwelling elderly of Assam. Natl $\mathrm{J}$ Community Med. 2016;7:368-71.

6. Chen S-F, Huang S-F, Lu L-T, Wang M-C, Liao J-Y, Guo J$L$. Patterns of perspectives on fall-prevention beliefs by community-dwelling older adults: a $\mathrm{Q}$ method investigation. BMC geriatrics. 2016;16(1):1-10.

7. Organization $\mathrm{WH}$, Ageing $\mathrm{WHO}$, Unit LC. WHO global report on falls prevention in older age: World Health Organization; 2008.

8. Bachani AM, Ghaffar A, Hyder AA. Burden of fall injuries in Pakistan--analysis of the National Injury Survey of Pakistan. Eastern Mediterranean health journal. 2011;17(5).

9. Gill TM, Murphy TE, Gahbauer EA, Allore HG. Association of injurious falls with disability outcomes and nursing home admissions in community-living older persons. American journal of epidemiology. 2013;178(3):418-25.

10. Sharif SI, Al-Harbi AB, Al-Shihabi AM, Al-Daour DS, Sharif RS. Falls in the elderly: assessment of prevalence and risk factors. Pharmacy Practice (Granada). 2018;16(3).

11. Woolcott JC, Richardson KJ, Wiens MO, Patel B, Marin J, Khan KM, et al. Meta-analysis of the impact of 9 medication classes on falls in elderly persons. Archives of internal medicine. 2009;169(21):1952-60.

12. Musich S, Wang SS, Ruiz J, Hawkins K, Wicker E. Fallsrelated drug use and risk of falls among older adults: a study in a US Medicare population. Drugs \& aging. 2017;34(7):555-65

13. Mortazavi H, Tabatabaeichehr M, Taherpour M, Masoumi M. Relationship between home safety and prevalence of falls and fear of falling among elderly people: a cross-sectional study. Materia socio-medica. 2018;30(2):103.

14. Orces $\mathrm{CH}$. Prevalence and determinants of falls among older adults in Ecuador: an analysis of the SABE I Survey. Current gerontology and geriatrics research. 2013;2013.

15. Pirrie M, Saini G, Angeles R, Marzanek F, Parascandalo J, Agarwal $G$. Risk of falls and fear of falling in older adults residing in public housing in Ontario, Canada: findings from a multisite observational study. BMC geriatrics. 2020;20(1):1-8

16. Wu H, Ouyang P. Fall prevalence, time trend and its related risk factors among elderly people in China. Archives of gerontology and geriatrics. 2017;73:294-9.

17. Gamage N, Rathnayake N, Alwis G. Prevalence and associated risk factors of falls among rural communitydwelling older people: A cross-sectional study from southern sri lanka. Current gerontology and geriatrics research. 2019;2019.

18. Patil S, Suryanarayana S, Dinesh R, Shivraj N, Murthy N. Risk factors for falls among elderly: A community-based study. International Journal of Health \& Allied Sciences. 2015;4(3):135-.

19. Lukaszyk C, Radford K, Delbaere K, Ivers R, Rogers K, Sherrington $C$, et al. Risk factors for falls among older Aboriginal and Torres Strait Islander people in urban and regional communities. Australasian journal on ageing. 2018;37(2):113-9.

20. D'souza SA, Shringarpure A, Karol J. CIRCUMSTANCES AND CONSEQUENCES OF FALLS IN INDIAN OLDER ADULTS. Indian Journal of Occupational Therapy (Indian Journal of Occupational Therapy). 2008;40(1).

21. Ravindran RM, Kutty VR. Risk factors for fall-related injuries leading to hospitalization among community-dwelling older persons: a hospital-based case-control study in Thiruvananthapuram, Kerala, India. Asia Pacific Journal of Public Health. 2016;28(1_suppl):70S-6S.

22. Ranaweera A, Fonseka $\mathrm{P}$, PattiyaArachchi A, Siribaddana S. Incidence and risk factors of falls among the elderly in the district of Colombo. Ceylon Medical Journal. 2013;58(3).

23. Zhang D, He Y, Liu M, Yang H, Wu L, Wang J, et al. Study on incidence and risk factors of fall in the elderly in a rural community in Beijing. Zhonghua liu xing bing xue za zhi= Zhonghua liuxingbingxue zazhi. 2016;37(5):624-8.

24. Lukaszyk C, Harvey L, Sherrington C, Keay L, Tiedemann A, Coombes $\mathrm{J}$, et al. Risk factors, incidence, consequences and prevention strategies for falls and fall-injury within older indigenous populations: a systematic review. Australian and New Zealand journal of public health. 2016;40(6):564-8 